\title{
Impact of tympanoplasty on tinnitus using tinnitogram
}

\author{
Original \\ Article \\ Aboulkheir $^{3}$ \\ ${ }^{1}$ Department of Otorhinolaryngology, Hearing and Speech Institute, ${ }^{2}$ Department of \\ Audiology, Hearing and Speech Institute, Giza, ${ }^{3}$ Department of Otorhinolaryngology, \\ Faculty of Medicine, Al Azhar University
}

Meaad Mohamed ${ }^{1}$, Abir Omara ${ }^{2}$,Wael Fawzy Essa ${ }^{3}$, Wafaie Abdelrasol Morad ${ }^{3}$, Mohamed

\begin{abstract}
Introduction: Chronic Suppurative otitis Media (CSOM) and tympanic membrane perforation are leading causes of mild to moderate conductive acquired hearing loss worldwide that may lead to tinnitus.

Aim: This study is designed to evaluate the postoperative various potential effects of tympanoplasty on tinnitus in patients with central tympanic membrane perforation using different methods of testing including tinnitogram.

Methods: This study was carried out in: Oto-rhinolaryngology department - El Azhar University Hospitals and Otorhinolaryngology department Hearing and Speech institute in Giza (from March 2016 to March 2018). One hundred ears with central tympanic membrane perforation of one hundred patients were included in this study and it was designed as a prospective randomized study. Typmpanoplasty was done for all the ears with preoperative and postoperative audiological assessment and tinnitogram and Tinnitus Handicap Inventory.

Results: Overall improvement by comparing pre-operative and post-operative results revealed that Tinnitus Handicap Inventory score improvement mean was (67.25), loudness threshold decrease mean was (35.71) and average Air Bone Gap improvement mean was (44.13).

Conclusion: Patients with tinnitus and hearing loss are excellent candidates to undergo tympanoplasty in order to control tinnitus by hearing improvement. Our study results proved that Repair of tympanic membrane perforation will improve hearing outcome and decrease burden of tinnitus complaint on patient's life.
\end{abstract}

Key Words: Tinnitus, tympanoplasty, tinnitus handicap inventory tinnitogram

Received: 05 January 2019, Accepted: 18 May 2019

Corresponding Author: Meaad Mohamed Meaad El-Sayed, Department of ENT, Al Azhar University, Al Hussien Hospital, Cairo, Egypt, Tel.: +2 01061692100, E-mail: midofarm@yahoo.com

ISSN: 2090-0740, November 2019 Vol.20, No.3

\section{INTRODUCTION}

Tympanoplasty is a common operation used to reconstruct the eardrum and ossicles, the main goals of treatment for CSOM are to relieve symptoms, rehabilitate hearing, and minimize complications and drainage ${ }^{[1]}$. Some patients, however, do not tolerate tinnitus and ask physicians about the results of surgery in relation to tinnitus ${ }^{[2]}$. Conventionally, tympanoplasty is performed under an operative microscope. Recently, endoscopic ear surgery is done all over the world ${ }^{[3]}$. The post-operative results of patients after surgical intervention of chronic suppurative otitis media are assessed by clinical examination and audiological evaluation ${ }^{[4]}$. However, the criteria for the post-tympanoplasty clinical improvement may not reflect the satisfaction expressed by the patient ${ }^{[5]}$. Although its association with exclusively conductive hearing loss is very little studied, it is full of relevance because the conductive component is more commonly reverted with treatment, when compared with its sensori-neural counterpart ${ }^{[6]}$.
AIM

This study is designed to evaluate the postoperative various potential effects of tympanoplasty on tinnitus in patients with central tympanic membrane perforation using different methods of testing including tinnitogram.

\section{METHODS}

This study was carried out in: Oto-rhinolaryngology department - El Azhar University Hospitals and Otorhinolaryngology department Hearing and Speech institute in Giza (from March 2016 to March 2018). One hundred ears with central tympanic membrane perforation of one hundred patients were included in this study and it was designed as a prospective randomized study. Typmpanoplasty was done for all the ears with preoperative and postoperative audiological assessment and tinnitogram and Tinnitus Handicap Inventory. The following factors were considered in this work: Site and 
Size of tympanic membrane perforation, Integrity of the ossicular chain, Presence or absence of middle ear adhesions or fibrotic bands, Exposure of the round window or Eustachian tube orifice through perforation, Type of graft used for tympanoplasty either [fascia or thinned chondro-perichondrium from tragal or conchal cartilage], Recorded unexpected middle ear pathology during surgery. Inclusion criteria: All patient aged 18-45 years old undergone tympanoplasty were included and we excluded patients with SNHL and medically unfit for surgery.

\section{Ethical committee}

This study followed all principles of declaration of Helsiniki and approved by El-Azhar ethical committee.

The evaluation of each patient was conducted pre-operatively and three months post operatively. The following was performed: Taking a thorough full medical history, Complete general and local examination including fairly comprehensive otologic examination. Completion of Tinnitus Handicap inventory (THI), Otoscopic examination and microscopic examination of the ear canal and tympanic membrane with detailed description of the findings. All patients under study were subjected to routine audiologic testing which provides an assessment of the patient's hearing and a basis for subsequent tinnitus measurement, using the following equipments: Sound treated room, (Amplisilence Model E), Two-channel pure tone audiometer: Interacoustics AC 40, caliberated according to the ISO standards, TDH 39 headphones and bone vibrator radio ear B71. Pure tone audiometry: Air conduction in the frequency range of $250-8000 \mathrm{~Hz}$., Bone conduction in the frequency range of $500-4000 \mathrm{~Hz}$.

Speech audiometry; including: Speech reception threshold (SRT), using Arabic (Soliman, et al 1985) ${ }^{[7]}$ spondaic words, Word discrimination score (WDS), using Arabic phoetically balanced (PB) words (Soliman 1976) ${ }^{[8]}$. Immittancemetry using Immittance meter: Interacoustics AZ 26 with single-cmponent, single-frequency probe tone $226 \mathrm{~Hz}$, calibrated according to the ISO standards.

Acoustic reflexes were presented contralaterally using headphones TDH 39 to test frequencies in frequency range (500-4000) in octave intervals. Specific tinnitus measurements (Tinnitogram) using same audiometer were applied to the contralateral ear (ear contralateral to perforated tympanic membrane with tinnitus): Tinnitus pitch match (TPM);We started at $1000 \mathrm{~Hz}$ and moved up and down in frequency, sometimes we used narrow band noise for pitch matching, Tinnitus loudness match (TLM); Patient threshold was determined at frequency of pitch matching, sound level was then increased in small steps (1 or $2 \mathrm{~dB}$ increments) until patient reported that specific tone was just equal in loudness to his tinnitus. The $\mathrm{dB}$ level of loudness match was in $\mathrm{dB}$ sensation level (dB SL) i.e. $\mathrm{dB}$ above threshold. Repetition was sometimes necessary to confirm reliability of measurements. Surgical intervention techniques: The patients were operated upon under supervision of the first two senior authors at ElAzhar university hospitals and senior staff of hearing and speech institute. All procedures were performed under general anesthesia, through a post auricular approach. In (66) ears of (66) patients, temporalis fascia including both superficial and deep layers was harvested through the retroauricular incision. (25) ears of (25) patients underwent harvesting tragal cartilage together with perichondrium on both sides through medial surface incision in tragus and subcutaneous inferior cut was made as low as possible to gain most of tragal cartilage.

The perichondrium was peeled at the convex side, The cartilage perichondrium graft was prepared by dissecting perichondrium off one side only, keeping the attachment of other side and the surface covered with perichondrium was directed laterally. Conchal chondro-perichondrium was harvested in (9) ears of (9) patients through same post auricular incision.

The choice of conchal cartilage was the surgeon's choice in (6) as this is his ordinary technique, one patient had deformed tragus, one patient had old trauma that resulted in tragus fracture and the latter patient had very thin tragal cartilage.

\section{Statistical analysis}

Data analysis was performed using the software SPSS (Statistical Package for the Social Sciences) version 20. Quantitative variables were described using their means and standard deviations. Categorical variables were described using their absolute frequencies.

Kolmogor $\neg$ ov-Smirnov (distribution-type) and Levene (homogeneity of variances) tests were used to verify assumptions for use in parametric tests. To compare means of two groups, independent sample $t$ test was used when appropriate

\section{RESULTS}

In the present study, 100 ears of 100 patients were included with no bilateral cases at same patient, patients age ranged from 18 to 40 years, they were 52 males and 48 females, 51 of them live in urban areas, majority of them(69) were nonsmokers and 23 of them smoke cigarette and 8 smoke Goza. All patients included in this study had central tympanic membrane perforation and complaining of tinnitus as one of their main complaints, besides 57 of them complained mainly from hearing loss, 39 from otalgia and 4 of them complained mainly from intermittent ear discharge. Overall improvement by comparing pre-operative and post-operative results revealed that THI score improvement mean was (67.25), loudness threshold decrease mean was (35.71) and average ABG improvement mean was (44.13) 
(Tables $1,2,4)$. There is statistically significant difference between percent change in THI and size of perforation and large perforation group of patients were the main cause of this result (Table 3). There is significant difference between presence of exposed round window, site of perforation and percent change in ABG (Tables 5,6). There are statistically significant differences between THI scores and loudness threshold pre-operatively and post-operatively within and between both groups (Table 7) (Figures 1,2).

Table 1: Comparison between preoperative and postoperative tinnitus handicap inventory (THI) findings of study patients

\begin{tabular}{lcccc}
\hline & Preop. & Postop. & Wilcoxon Test & Pvalue \\
\hline Score : & & & & \\
Median & 68 & 22 & -8.694 & $<0.001^{* *}$ \\
Range & $28-94$ & $6-52$ & & \\
Grade: & & & & \\
Median & 4 & 2 & -8.841 & $<0.001^{* *}$ \\
Range & $2-5$ & $1-3$ & & \\
$* * * 00.001$ is highly significant & & &
\end{tabular}

Table 2: Relations between preoperative data and improvement in THI

\begin{tabular}{|c|c|c|c|}
\hline & THI $\%$ change & \multirow{2}{*}{$\mathrm{t}$} & \multirow{2}{*}{$p$} \\
\hline & Mean \pm SD & & \\
\hline \multicolumn{4}{|l|}{ Exposed round window: } \\
\hline Noise exposure & $68.1 \pm 7.48$ & \multirow[t]{2}{*}{0.759} & \multirow[t]{2}{*}{0.348} \\
\hline No noise exposure & $65.69 \pm 17.92$ & & \\
\hline \multicolumn{4}{|l|}{ Exposed Eustachian tube: } \\
\hline Absent & $67.56 \pm 11.51$ & \multirow[t]{2}{*}{0.400} & \multirow[t]{2}{*}{0.690} \\
\hline Present & $66.47 \pm 13.86$ & & \\
\hline \multicolumn{4}{|l|}{ Site of perforation: } \\
\hline Antro-superior portion & $69.29 \pm 9.93$ & \multirow{4}{*}{$\mathrm{F}=1.379$} & \multirow{4}{*}{0.254} \\
\hline Antro-inferior portion & $64.98 \pm 15.92$ & & \\
\hline Postro-inferior portion & $67.27 \pm 8.87$ & & \\
\hline Postro-superior portion & $71.53 \pm 4.71$ & & \\
\hline \multicolumn{4}{|l|}{ Size of perforation: } \\
\hline Small & $69.38 \pm 6.96$ & \multirow{3}{*}{$F=7.592$} & \multirow{3}{*}{$0.001 * *$} \\
\hline Medium sized & $69.81 \pm 8.18$ & & \\
\hline Large & $58.95 \pm 12.15^{\infty}$ & & \\
\hline
\end{tabular}

Table 3: Relations between intra-operative data and improvement in THI

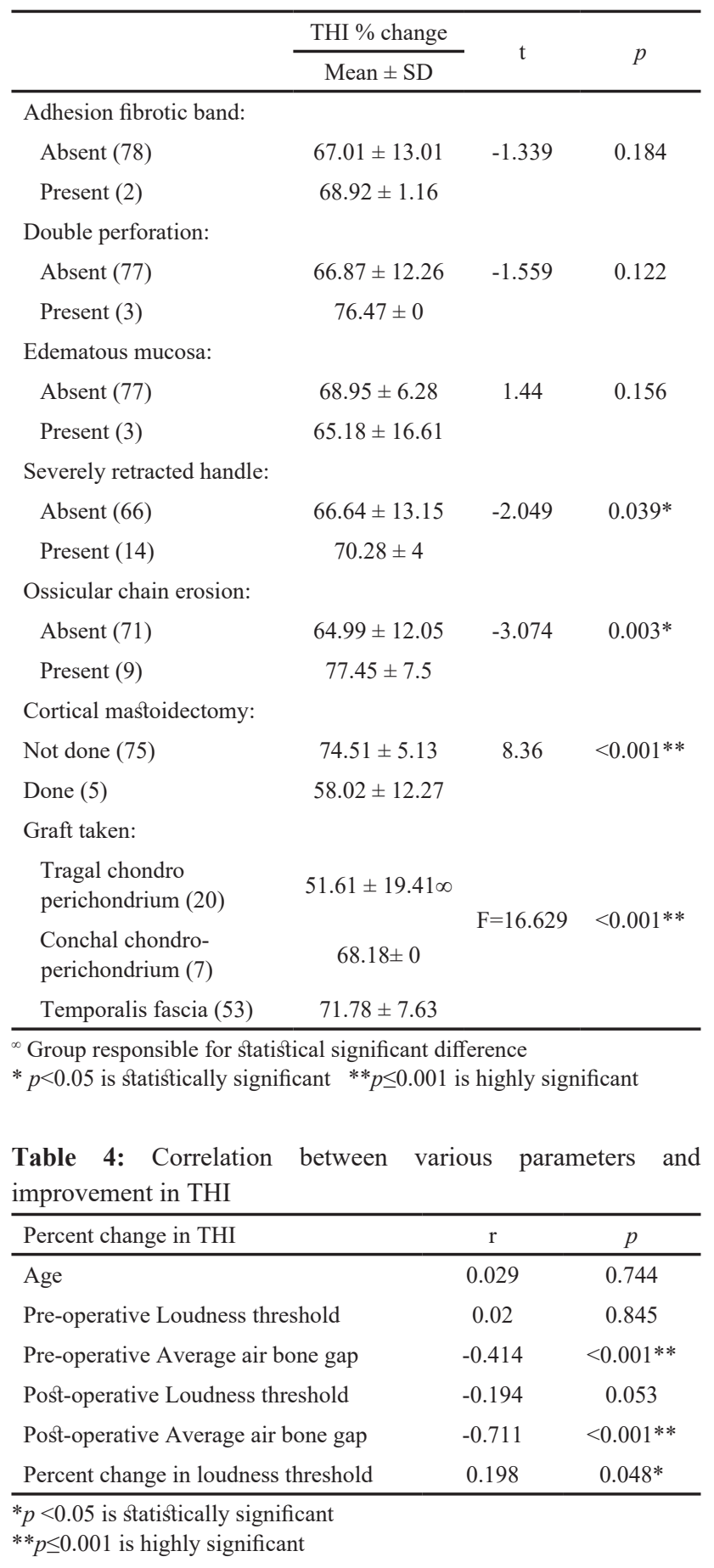


Table 5: Pre-operative data and improvement in average air bone gap

\begin{tabular}{|c|c|c|c|}
\hline & \multicolumn{2}{|c|}{ improvement in $\mathrm{ABG}$} & \multirow{2}{*}{$p$} \\
\hline & Mean \pm SD & $\mathrm{t}$ & \\
\hline \multicolumn{4}{|l|}{ Exposed round window: } \\
\hline Absent (52) & $41.18 \pm 15.37$ & \multirow[t]{2}{*}{-2.905} & \multirow[t]{2}{*}{$0.005^{*}$} \\
\hline Present(28) & $49.6 \pm 10.32$ & & \\
\hline \multicolumn{4}{|l|}{ Exposed Eustachian tube: } \\
\hline Absent (58) & $44.64 \pm 15.45$ & \multirow[t]{2}{*}{0.570} & \multirow[t]{2}{*}{0.570} \\
\hline Present (22) & $42.81 \pm 11.09$ & & \\
\hline \multicolumn{4}{|l|}{ Site of perforation: } \\
\hline Antro-superior (6) & $31.25 \pm 6.68 \infty 0$ & \multirow{4}{*}{$F=3.657$} & \multirow{4}{*}{$0.015^{*}$} \\
\hline Antro-inferior (35) & $42.22 \pm 15.82$ & & \\
\hline Postro-inferior (24) & $47.35 \pm 10.74$ & & \\
\hline Postro-superior (15) & $48.27 \pm 15.09$ & & \\
\hline \multicolumn{4}{|l|}{ Size of perforation: } \\
\hline Small (11) & $42.25 \pm 13.16$ & \multirow{3}{*}{$\mathrm{F}=0.907$} & \multirow{3}{*}{0.407} \\
\hline Medium sized (51) & $43.26 \pm 14.72$ & & \\
\hline Large (18) & $47.61 \pm 13.91$ & & \\
\hline
\end{tabular}

Table 6: Intraoperative data and improvement in average bone gap

\begin{tabular}{|c|c|c|c|}
\hline & \multicolumn{2}{|c|}{ improvement in $\mathrm{ABG}$} & \multirow{2}{*}{$p$} \\
\hline & Mean \pm SD & $\mathrm{t}$ & \\
\hline \multicolumn{4}{|l|}{ Adhesion fibrotic band: } \\
\hline Absent (78) & $42.46 \pm 14.67$ & -8.098 & $<0.001 * *$ \\
\hline Present (2) & $55.24 \pm 0.49$ & & \\
\hline \multicolumn{4}{|l|}{ Double perforation: } \\
\hline Absent (77) & $43.4 \pm 14.17$ & -12.538 & $<0.001 * *$ \\
\hline Present (3) & $61.54 \pm 0$ & & \\
\hline \multicolumn{4}{|l|}{ Edematous mucosa: } \\
\hline Absent (77) & $40.67 \pm 15.79$ & -2.748 & $0.005^{*}$ \\
\hline Present (3) & $48.34 \pm 11.11$ & & \\
\hline \multicolumn{4}{|l|}{ Severely retracted handle: } \\
\hline Absent (66) & $41.14 \pm 13.82$ & -9.039 & $<0.001 * *$ \\
\hline Present (14) & $58.72 \pm 4.65$ & & \\
\hline \multicolumn{4}{|l|}{ Ossicular chain erosion: } \\
\hline Absent (71) & $43.05 \pm 14.79$ & -4.967 & $<0.001^{* *}$ \\
\hline Present (9) & $52.87 \pm 3.98$ & & \\
\hline \multicolumn{4}{|l|}{ Cortical mastoidectomy: } \\
\hline Not done (75) & $45.61 \pm 16.84$ & 1.234 & 0.122 \\
\hline Done (5) & $42.24 \pm 10.21$ & & \\
\hline \multicolumn{4}{|l|}{ Graft taken: } \\
\hline $\begin{array}{l}\text { Tragal chondro- } \\
\text { perichondrium (20) }\end{array}$ & $40.41 \pm 11.25$ & 158 & $0028 *$ \\
\hline $\begin{array}{l}\text { Conchal chondro- } \\
\text { perichondrium (7) }\end{array}$ & $55.56 \pm 0 \infty$ & $=3.158$ & $0.028^{\circ}$ \\
\hline Temporalis fascia (53) & $44.42 \pm 14.34$ & & \\
\hline
\end{tabular}

Table 7: Intraoperative data and improvement in average bone gap

\begin{tabular}{|c|c|c|c|c|}
\hline & \multicolumn{2}{|c|}{ Pre-op. Average air bone gap } & \multirow{3}{*}{$\mathrm{t}$} & \multirow{3}{*}{$p$} \\
\hline & $\begin{array}{l}\text { Group } 1 \\
(<15 \mathrm{db})\end{array}$ & $\begin{array}{l}\text { Group } 2 \\
(\geq 15 \mathrm{db})\end{array}$ & & \\
\hline & Mean \pm SD & Mean \pm SD & & \\
\hline $\begin{array}{c}\text { Pre-operative } \\
\text { THI }\end{array}$ & $40 \pm 12.83$ & $70.52 \pm 12.04$ & -6.843 & $<0.001 * *$ \\
\hline $\begin{array}{c}\text { Post-operative } \\
\text { THI }\end{array}$ & $9 \pm 3.21$ & $23.63 \pm 9.72$ & -4.211 & $<0.001 * *$ \\
\hline $\begin{array}{c}\text { Paired sample } \\
\text { t test }\end{array}$ & 9.113 & 36.001 & & \\
\hline $\mathrm{p}$ & $<0.001 * *$ & $<0.001 * *$ & & \\
\hline $\begin{array}{c}\text { Pre-operative } \\
\text { loudness } \\
\text { threshold }\end{array}$ & $25 \pm 5.35$ & $46.7 \pm 9.41$ & -6.411 & $<0.001^{* *}$ \\
\hline $\begin{array}{c}\text { Post-operative } \\
\text { loudness } \\
\text { threshold }\end{array}$ & $18 \pm 5.35$ & $29.68 \pm 10.61$ & -3.071 & $0.003 *$ \\
\hline $\begin{array}{l}\text { Paired sample } \\
\text { t test }\end{array}$ & & 14.798 & & \\
\hline $\mathrm{p}$ & & $<0.001 * *$ & & \\
\hline
\end{tabular}

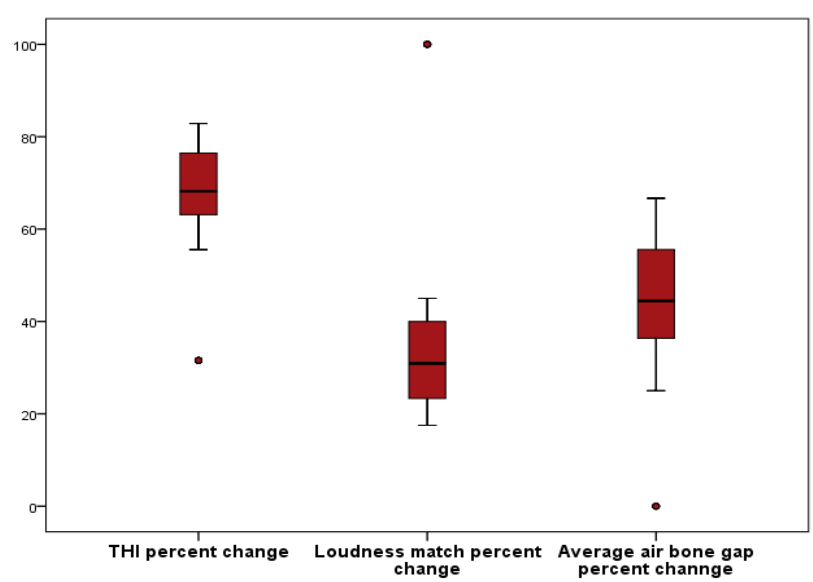

Fig. 1: Boxplot showing percent change in THI, loudness match and average air bone gap

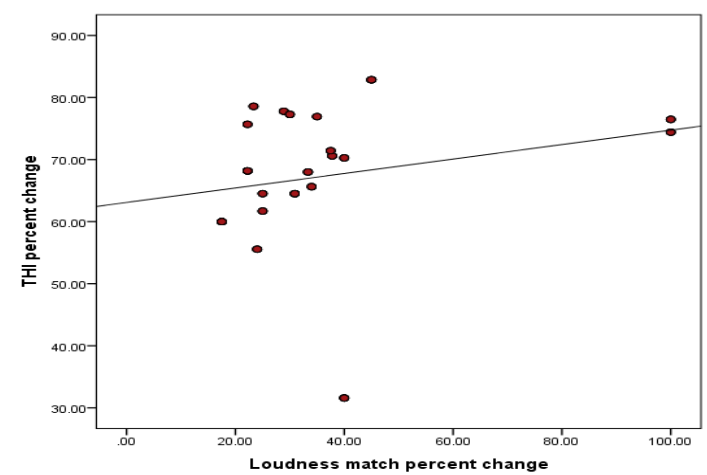

Fig. 2: scatter graph showing insignificant positive correlation between percent change in loudness match and percent change in THI 


\section{DISCUSSION}

Tinnitus is considered as an abnormal activity of the auditory pathway, usually interpreted as a sound by the central nervous system. The association between tinnitus and hearing loss happens in 85 to $96 \%$ of the cases ${ }^{[6]}$. Tympanoplasty usually improve tonal thresholds and the favorable tinnitus results are very likely a consequence of this improvement, since the proper vibration of middle ear fluids re-establishes both afferent and efferent stimuli.

We planned our study to exclude patients who have or developed sensori-neural or mixed hearing loss preoperatively and in the postoperative follow up period in order to exclude tinnitus that is caused by this component. We think that patients with milder hearing loss and concomitant tinnitus mostly will have significant hearing gain and tinnitus improvement.

Saito et al. (1999) ${ }^{[9]}$ reported tinnitus improvement in $50 \%$ of the patients by different middle ear diseases; of those, 22 are cases of chronic otitis media, five of chronic cholesteatomatous otitis media, two of ossicular chain malformations and one of otospongiosis. Differently from this, Helms (1981) ${ }^{[10]}$ reported tinnitus remission after surgery in $1 / 3$ of the patients, also remaining unaltered and getting worse in $1 / 3$, respectively. Hearing loss, even with a primary conductive characteristic, causes a reduction in afferent stimuli of the central auditory pathways. Since the efferent pathways have modulating properties, hearing loss reduces its suppressive action because it is no longer necessary. The efferent pathways dysfunction is one of the possible mechanisms causing tinnitus.

\section{CONCLUSION}

Patients with tinnitus and hearing loss are excellent candidates to undergo tympanoplasty in order to control tinnitus by hearing improvement (Figures 3,4). We recommend Tinnitus Handicap Inventory as a self-report measure that can be used in a busy clinical practice to quantify the impact of tinnitus on daily living. Also, Tinnitogram is a reliable accurate technique for tinnitus accurate testing.

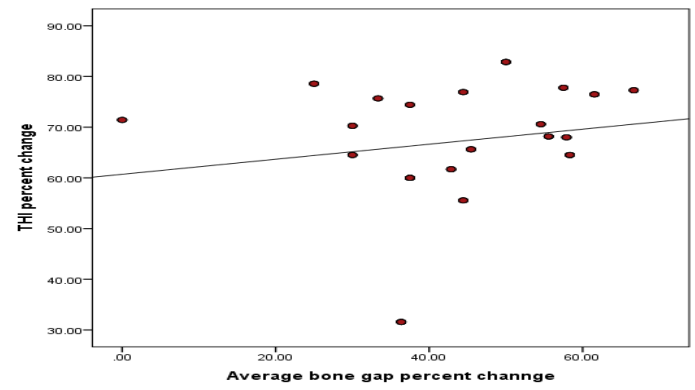

Fig. 3: scatter-dot showing insignificant positive correlation between percent change in $\mathrm{ABG}$ and percent change in THI

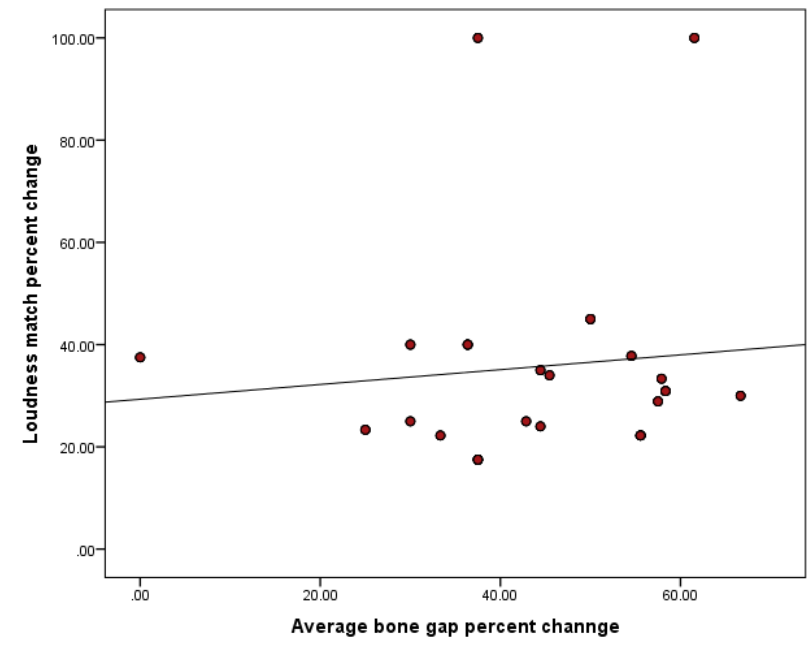

Fig. 4: scatter dot showing insignificant positive correlation between percent change in $\mathrm{ABG}$ and percent change in loudness match

\section{CONFLICT OF INTERESTS}

There are no conflict of interest

\section{REFERENCES}

1. Hardman J, Muzaffar J, Nankivell P, Coulson C.(2015).Tympanoplasty for chronic tympanic membrane perforation in children: systematic review and meta-analysis. Otol Neurotol;36:796e804.

2. Lima JCBD, Marone SAM, Martucci O, Gonçalez F, Silva Neto JJD, Ramos ACM.(2011). Evaluation of the organic and functional results of tympanoplasties through a retro-auricular approach at a medical residency unit. Brazilian journal of otorhinolaryngology; 77(2): 229-36.

3. Kim HC, Jang CH, Kim YY, Seong JY, Kang SH, Cho YB.(2016). Role of preoperative air-bone gap in tinnitus outcome after tympanoplasty for chronic otitis media with tinnitus. Braz JOtorhinolaryngol. http://dx.doi.org/10.1016/j.bjorl.2017.01.003.

4. Hughes I.J. and Dowling A.P.(2017).The absorption of sound by per forated linings. Journal of Fluid Mechanics, 218:299-335, 1990. RienstraHirschberg 12 Apr, 20:00 Bibliography 279.

5. Mane R, Patil B, Mohite A, Varute VV.(2013). Bilateral type 1 tympanoplasty in chronic otitis media. Indian Journal of Otolaryngology and Head \& Neck Surgery; 65(4): 293-7.

6. Stein A, Wunderlich R, Lau P, Engell A, Wollbrink A, Shaykevich A, Kuhn JT, Holling H, Rudack C, Pantev C. (2016) Clinical trial on tonal tinnitus with tailor-made notched music training. BMC Neurol.;16:38. doi: 10.1186/s12883-016-0558-7. 
7. Soliman S, Fathalla A, Shehata W. (1985) Development of the Arabic Staggered Spondaic Words (SSW) Test. Proceedings of the 8th Annual Ain Shans Congress 1985; 2 pp 1220-1246.

8. Soliman S. (1976). Speech discrimination audiometry using Arabic phonetically balanced words. Ain Shams Medical Journal, 27 pp 27-30.
9. Saito T et al.(1999).Efficacy of middle ear surgery for patients with hearing aids and middle ear disease. Nippon JibiinkokaGakkai Kaiho;102(3) pp 347-53.

10. Helms J.(1981).Tympanoplastik und Ohrgerausche. LaryngolOtol; 60: 99-100. 